\title{
Hard layers based on metal borides: Microstructure and mechanical properties
}

Martín Ortiz-Domínguez ${ }^{1}$, Arturo Cruz-Avilés ${ }^{1}$, Ángel Morales-Robles², Oscar Gómez-Vargas ${ }^{3}$, José Solís-Romero $^{3}$, Jorge Zuno-Silva ${ }^{1}$ and Edgar Cardoso-Legorreta ${ }^{2}$

${ }^{1}$ Universidad Autónoma del Estado de Hidalgo, Ciudad Sahagún, Hidalgo, Mexico, ${ }^{2}$ Universidad Autónoma del Estado de Hidalgo, Mineral de la Reforma, Hidalgo, Mexico, ${ }^{3}$ Instituto Tecnológico de Tlalnepantla, Estado de México, México, Mexico

Hard layers with a thickness of a few microns are widely applied to improve the performance of tools, for example, for cutting, forming and casting applications, and components, for example, in automotive and aerospace applications. The losses caused by friction and tribological wear are adding up to extremely high figures. Interpolation of data from 1985 shows that in 2000 economic losses in Germany are adding up to approximately $2-3 \%$ of the gross national product. This equates to between $€ 30$ billion and $€ 40$ billion per year. These costs for losses are caused by friction losses by machine stops and repair and production losses and losses due to an insufficient product quality. Several families of coatings have been developed during the past 30 years [1-10]. In particular, boride layer yields a high surface hardness, good tribological properties and moderate oxidation resistance at high temperature. Particularly, the morphology of boride layers in the ferrous alloys depends upon the alloying elements present in the matrix. The current work aimed to analyze the microstructure and wear properties of the Fe2B layers formed on an AISI S1 steel surface have been investigated at different temperatures by the powder-pack process. For tribological characterization, the hardness of the boride layers was measured by means of a Vickers indenter (DuraScan 20 G5) with a load of $50 \mathrm{~g}$, the Daimler-Benz Rockwell-C indentation technique was used to qualitatively assess the cohesion of boride layers on AISI S1. Furthermore, the pin-on-disc test was employed in order to study the effect of the boriding treatment on wear behaviour of this steel. The specimen sizes are following MPIF STANDARD 41, the tested samples had a disc shape with a diameter of $25.4 \mathrm{~mm}$ and a thickness of $10 \mathrm{~mm}$. The chemical composition of the material is: $0.40-0.55 \% \mathrm{C}, 1.00-$ $1.80 \% \mathrm{Cr}, 0.10-0.40 \% \mathrm{Mn}, 0.15-1.20 \% \mathrm{Si}, 0.15-0.30 \% \mathrm{~V}, 1.50-3.00 \% \mathrm{~W}, 0.03 \% \mathrm{P}$ and $0.03 \% \mathrm{~S}$. Dehydrated paste-pack boriding procedure was preferred in this study for its cost-effectiveness, and simplicity of the required equipment. The samples were embedded in a closed in a closed cylindrical case (see Fig. 1) having a dehydrated paste of boron powder mixture inside with an average particle size of 10 $\mu \mathrm{m}$. Boriding mixture contains of $\mathrm{B} 4 \mathrm{C}, \mathrm{Na} 3 \mathrm{AlF} 6, \mathrm{SiC}$, and $\mathrm{SiC} 8 \mathrm{H} 20 \mathrm{O} 4$ which is used to protect surfaces (see Fig. 2). The thermochemical process was carried out in a conventional furnace, maintaining a pure argon atmosphere, to eliminate the oxidation of the boron released in the chemical reaction of the boriding medium at 1123 for $4 \mathrm{~h}$ and $1273 \mathrm{~K}$ for $6 \mathrm{~h}$ of exposure respectively. The hard samples were grinded with $\mathrm{SiC}$ abrasive paper up to grit 2500. Afterwards, the samples were polished using a diamond suspension with particle size of $6 \mu \mathrm{m}$, finishing with particle size of $3 \mu \mathrm{m}$. Figure 3 shows the cross-sections and the EDS analysis obtained by SEM of boride layers on AISI S1 steel treated at $1273 \mathrm{~K}$ for $4 \mathrm{~h}$. The morphology of produced hard layers was saw-toothed for all boriding conditions. Such observed peculiar morphology favoured the adhesion of boride layers on borided steels [11]. In addition, the occurrence of more or less pronounced saw-tooth morphology depends mainly on the concentration of alloying elements present in the matrix as observed in different ferrous alloys [12]. The cohesion of boride layers on AISI S1 steel was investigated by using the Daimler-Benz Rockwell-C indentation technique. Two borided samples treated 
(at $1123 \mathrm{~K}$ for $4 \mathrm{~h}$ and $1273 \mathrm{~K}$ for $6 \mathrm{~h}$ ) were then subjected to the cohesion tests. The damage around the indentation can be viewed by SEM and compared with a defined pattern of adhesion strength according to the VDI 3198 norm [13-14]. The damage to the boride layer was compared with the adhesion strength quality maps HF1-HF6. Figure 4 shows the SEM micrographs of the craters of indentation caused by applying a conical diamond indenter on the surfaces of tested samples. Radial cracks are generated at the perimeter of indentation as shown in Figure 4(a). The adhesion quality was found to be acceptable for the sample borided at $1123 \mathrm{~K}$ for $4 \mathrm{~h}$ according to $\mathrm{H} 4$ category. Figure 4(b) puts into evidence the presence of a small quantity of spots with flaking due to extended delamination at the vicinity of the indentation. The adhesion quality was also acceptable for the borided sample at $1273 \mathrm{~K}$ for $6 \mathrm{~h}$, following HF3 category. The cross-sectional indentation marks and the hardness profile is shown in Figure 5(a) and (b), respectively. The tribological tests caused wear scars on the flat specimens (discs). There were measurable grooves on the discs. The wear depth of each groove was measured using a Mitutoyo Surftest Profilometer with the JIS2001 norm. Due to the depth measurements were taken. The experimental average depth was taken from these measurements. The volume of a "perfect groove" could be calculated from this information as done in earlier studies. The profiles are shown in Figure 6(a) and (b) show grooved features, demonstrating the two-body wear mechanism. Figure 6(a) indicates that the unborided surface of AISI S1 steel was more severely worn compared to the borided surface as shown in Figure 6(b). The wear behaviour of boride layers was investigated by performing the pin-on-disc test on both borided sample (at $1273 \mathrm{~K}$ for $6 \mathrm{~h}$ ) and untreated sample using a CSM tribometer. Figure 7, describes the evolution of friction coefficient as a function of sliding distance by comparing the frictional behaviour between borided and untreated samples. This pin-on-disc test was carried out by using a diamond indenter during sliding under dry conditions. It is noted that the borided sample has a friction coefficient lower than that of the unborided sample. The average friction coefficient for the untreated sample ranged from 0.306 to 0.295 while for the borided sample, it possesses a value of friction coefficient located between 0.370 and 0.350 . 


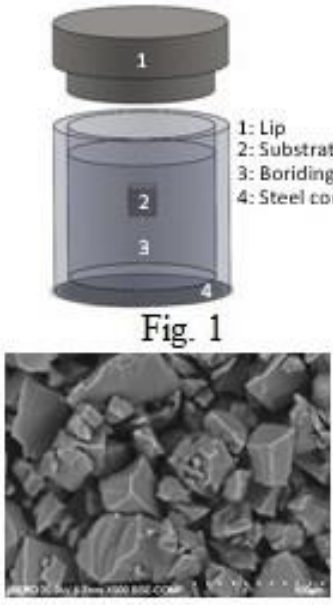

Fig. 2

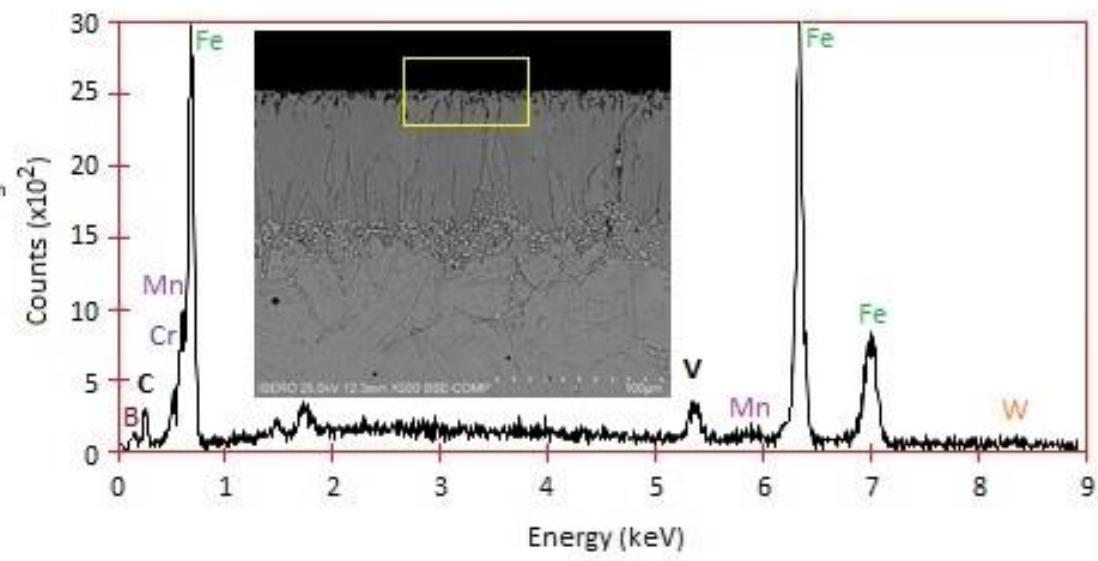

Fig. 3
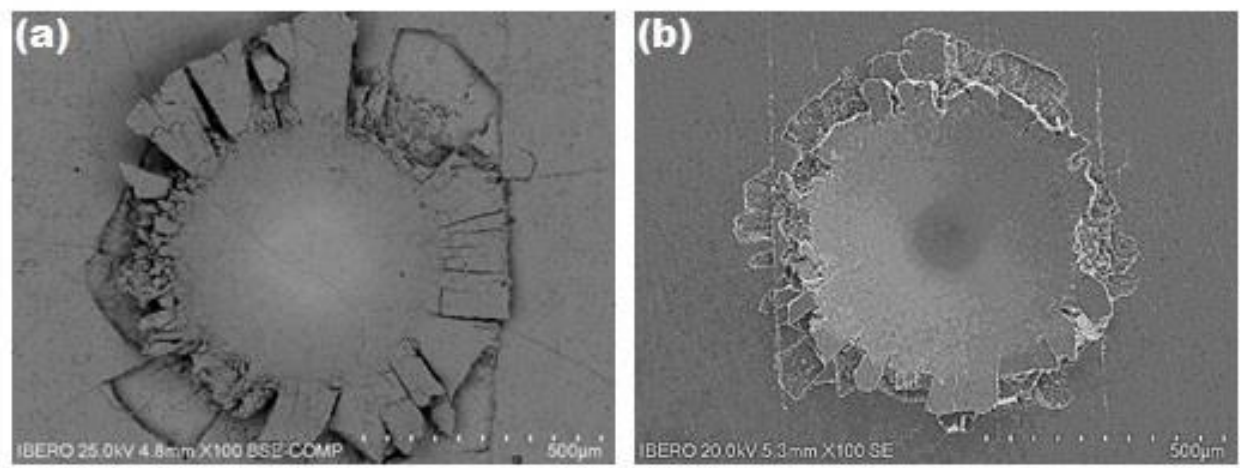

Fig. 4

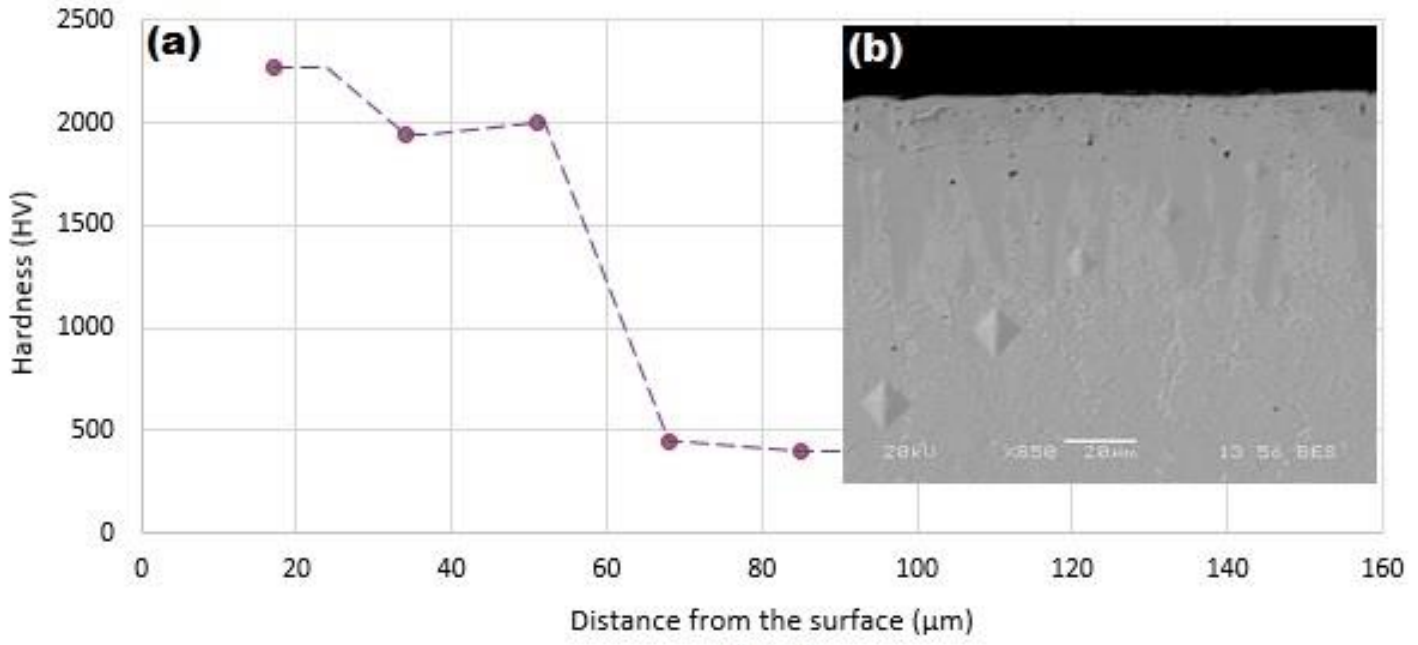

Fig. 5

Figure 1. Schematic view of the stainless steel AISI 316L container for the powder-pack treatments, Powder nitriding medium (Figure 1), Powder boriding medium (Figure 2), SEM cross-sectional micrograph and EDS spectrum at surface of the Fe2B layer developed on the surface of AISI S1 steel with $1273 \mathrm{~K}$ for $6 \mathrm{~h}$ (Figure 3) and SEM micrograph center of the indentation of VDI adhesion test on the borided AISI S1 steel samples: Figure 4(a) At a temperature of $1123 \mathrm{~K}$ with $4 \mathrm{~h}$ of exposure and Figure 4(b) with $6 \mathrm{~h}$ of exposure. Figure 5(a) Vickers indentation tests across the AISI S1 boride layer formed at a boriding temperature of $1123 \mathrm{~K}$ for $4 \mathrm{~h}$ of exposure time, (b) Hardness-depth profile obtained in cross- 
section along the ASI S1 boride layer formed at boriding temperature of $1123 \mathrm{~K}$ for $4 \mathrm{~h}$ of exposure time. The applied load was $0.5 \mathrm{~N}$.
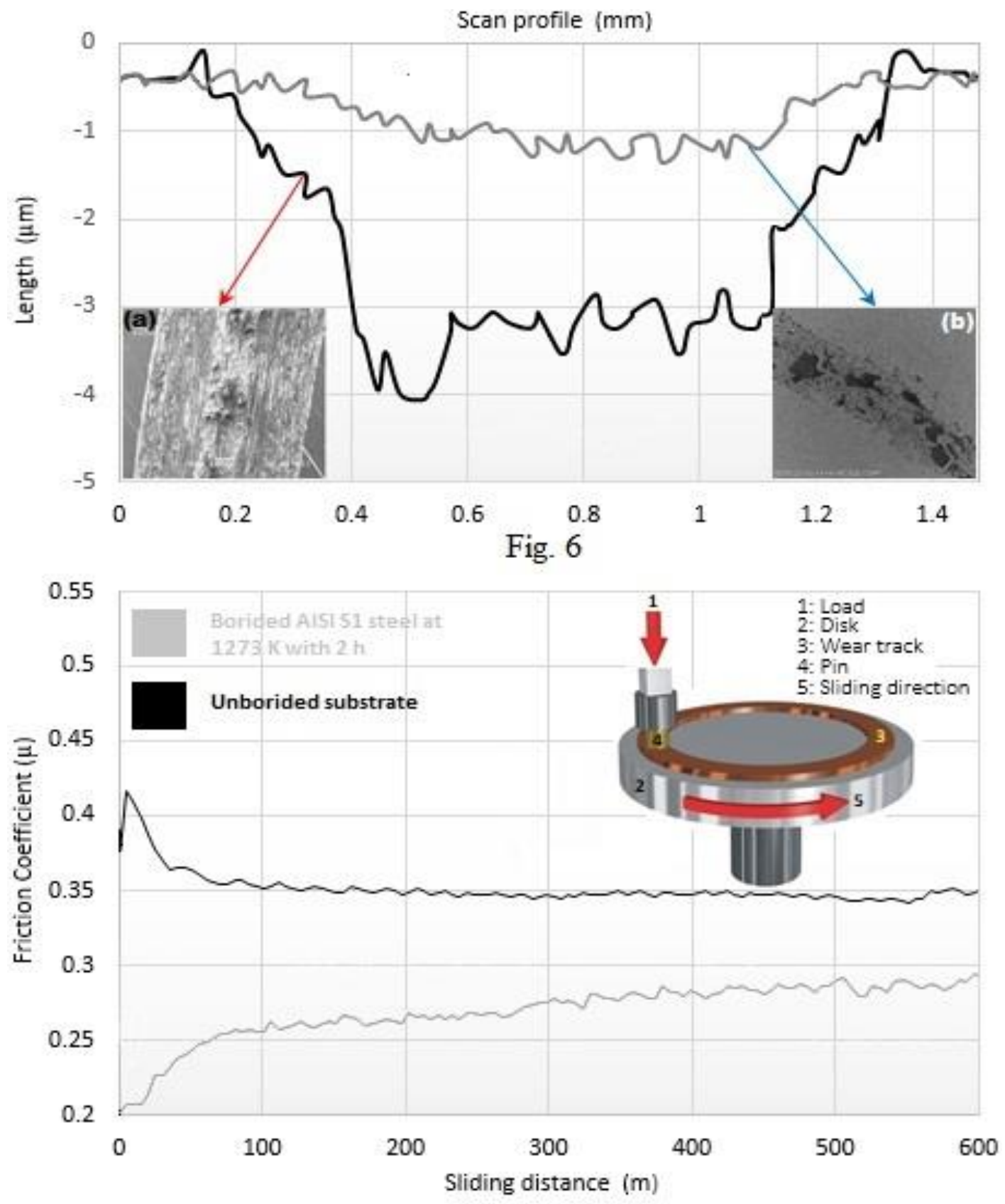

Fig. 7

Figure 2. Wear scar depth of the diamond-made indenter with a $10 \mathrm{~mm}$ diameter hemispheric, commonly employed, and was used to slide against on: 6(a) unborided AISI S1 steel and 6(b) borided at temperature $1273 \mathrm{~K}$ for $6 \mathrm{~h}$. Likewise, the variation of friction coefficient of diamond indenter during sliding against borided surface at $1273 \mathrm{~K}$ with exposure time of $6 \mathrm{~h}$ and unborided substrate (Figure 7). 


\section{References}

[1] J. R. Davis. "Surface Hardening of Steels: Understanding the Basics", 1st ed. ASM, Ohio, p. 213.

[2] M. Ortiz-Domínguez, I. Morgado-González, A. Cruz-Avilés, A. Soto-García, R. Trujillo-Sánchez, M. L. Moreno-González, G. Moreno-González, O. A. Gómez-Vagas, J. Zuno-Silva, Microsc.Microanal. 25 (Suppl 2) 2019, p. 2400.

[3] M. Ortiz-Domínguez, O. A. Gómez-Vargas, I. Simón-Marmolejo, M. A. Flores-Rentería, L. E. Martínez-Martínez, A. Cruz-Avilés, M. A. Paredes-Rueda, Microsc. Microanal. 24 (Suppl 1) 2018, p. 1076.]

[4] O. A. Gómez-Vagas, M. Ortiz-Domínguez, A. Cruz-Avilés, I. Morgado-González, J. Solis-Romero, V. A. Castellanos-Escamilla, E. Coronel-Guerra, E. Cardoso-Legorreta, Microsc. Microanal. 25 (Suppl 2) 2019, p. 770.

[5] O. A. Gómez-Vargas, M. Ortiz-Domínguez, J. Solís-Romero, A. Arenas-Flores, I. Morgado González, J. Zuno-Silva, F. R. Barrientos-Hernández and J. Medina-Marín, Microsc. Microanal. 25 (Suppl 2) 2019, p. 796.

[6] M. Ortiz-Domínguez, O. A. Gómez-Vargas, G. Ares de Parga, G. Torres-Santiago, R. VelázquezMancilla, V. A. Castellanos-Escamilla, J. Mendoza-Camargo, and R. Trujillo-Sánchez, Advances in Materials Science and Engineering. 2019 (2019), p. 1.

[7] Graf von Matuschka A. "Boronizing", 1st ed. Carl Hanser Verlag, Munich, p. 12.

[8] K. H. Habig, Mater. Eng. 2 (1980), p. 83.

[9] Martín Ortiz-Domínguez, Ángel Morales-Robles, Oscar Gómez-Vargas José Solís-Romero, Microsc. Microanal. 26 (Suppl 2) 2020, p. 2220.

[10] Martin Ortiz-Domínguez, Mourad Keddam, Milton Elias-Espinosa, Marius RamírezCardona, Alberto Arenas-Flores, Jorge Zuno-Silva, Felipe Cervantes-Sodi and Edgar Cardoso-Legorreta, Metall. Res. Technol. 116 (2019), p. 11.

[11] T.S. Eyre, Wear. 34 (1975), p. 383.

[12] M. Carbucicchio, G. Palombarini, J. Mater. Sci. Lett. 10 (1987), p. 1147.

[13] N. Vidakis, A. Antoniadis, N. Bilalis, J. Mater. Process. Technol. 481 (2003), p. 143.

[14] S. Taktak, Mater. Des. 28 (2007), p. 1836. 